\title{
Effects of information relevance on decision making in complex environments*
}

\author{
SUSAN C. STREUFERT \\ Purdue University, West Lafayette, Indiana 47907
}

\begin{abstract}
Previous research based on predictions of complexity theory has often varied information load and measured characteristics of group decision making. A reinterpretation of related data on success and failure effects suggests that the obtained load effects may be confounded by simultaneous variation of information load and information relevance. To begin studying the separate effects of the two variables, information load was held constant at the previously determined optimal level and information relevance was varied as a proportion of load. It was found that integrated decision making (a complex decision response) was modified by changes in information relevance; but that respondent decision making and information search (simple decision responses) did not change. The results were tentatively interpreted to suggest that complex decision making varies with relevance, while simple decision making varies with information load. It was suggested that complexity theory might be correspondingly modified.
\end{abstract}

Interactive complexity theory (Driver \& Streufert, 1966, 1969; Schroder, Driver, \& Streufert, 1967; Streufert, 1970) has been concerned with the effects of environmental variables on complex human behavior in social situations, e.g., on group decision making. The theory is concerned with a number of predictor variables included in the "environmental complexity" concept. These variables are (1) information load, or the quantity of information received by a decision making group per unit time, (2) noxity, or the failure proportion of that information, and (3) eucity, or the success proportion of that information. It is assumed that load, noxity, and eucity "add" in some fashion into a joint effect. Predictions are made for environmental complexity effects on (1) integrated (strategic) decision making, (2) respondent (unintegrated nonstrategic) decision making (where each decision is associated with an incoming item of information in a one-to-one fashion), and (3) information search and other dependent variables. The theory predicts that increasing environmental complexity should produce initial increases and later decreases (an inverted U-shaped function) in integrated decision making, and that it should result in decreasing information search and increasing respondent decision making.

Early work testing the predictions of interactive complexity theory used the information load component of the environmental complexity compound as its independent variable. Success and failure levels were held constant. The various predictions of the theory were clearly supported (e.g., Streufert \& Driver, 1965, 1967; Streufert, Driver, \& Haun, 1967; Streufert \& Schroder; 1965; Streufert, Suedfeld, \& Driver, 1965). Subsequently, research was designed to test for the

*This work was supported by a contract between the Office of Naval Research and Purdue University. effects of the other two environmental complexity components (i.e., success and failure). This research failed to support many of the propositions of complexity theory. Particularly, success manipulations produced data which contradicted several complexity predictions. Based on a series of previous studies (e.g., Streufert, 1969, 1970, 1972; Streufert \& Castore, 1971), Streufert $(1970,1972)$ suggested that the success (eucity) and failure (noxity) "components" of environmental complexity may in effect reduce to information load. In complex decision making environments, failure information requires dealing with a new situation plus (in most cases) making the erroneous decision over again, while success information may eliminate the necessity for responding altogether. In other words, while failure information can be conceived as "doubled" information load, success information may in effect reduce or eliminate information load.

This "reinterpretation" of the load concept departs from the easily measurable "number of information items per unit time" concept and appears somewhat cumbersome. A more reasonable alternative may be the application of the information relevance ${ }^{1}$ concept. Relevant information is usually viewed as any information to which a meaningful task-oriented response is possible. Although the effects of information relevance on human behavior have been frequently studied in areas of human experimental psychology (e.g., signal detection, perception, concept formation), they have not been considered in social psychology in general or by workers concerned with complexity theory in particular. Unfortunately, the findings of previous relevance research are not conclusive. While most data appear to suggest that increases in irrelevant information decrease performance to criterion (e.g., Edmonds \& Mueller, 1970; Giambra, 1969; Goldstein \& Allen, 1971; Hodge \& Reid, 1971; Hyman, 1971; Scandura \& 
Voorhies, 1971; Well, 1971; Williges, 1971), some researchers have obtained contradictory results (e.g., Erlick, 1962; Kepros \& Bourne, 1966; Morgan \& Alluisi, 1967; Landis, Slivka, \& Silver, 1970; Tresselt, 1969). Some data even suggest that decreasing performance (to criterion) occurs with increasing relevant information as well, or occurs with increases in both relevant and irrelevant information (e.g., Campbell, 1968; Burron, Carlson, Getty, \& Jackson, 1971). Identical results for increases in relevant and irrelevant information suggest that the obtained results may be due to information load. Further, the fact that some researchers have obtained increases while others have obtained decreases in performance with increasing relevant and/or irrelevant information appears reminiscent of the inverted U-shaped function between load and complex performance proposed by complexity theory. However, in spite of these similarities, there may be few grounds for attempting to apply relevance research from signal detection, concept formation, or perception to the complex decision making tasks which have been employed in tests of complexity theory. Not only are the tasks widely divergent, but -and probably more importantly-the results obtained with relevance manipulations in other settings are as yet too unclear to permit an understanding of the underlying phenomena.

An application of the relevance concept to complexity predictions and research would consequently require testing an operationalization of that concept in a complex decision making setting. How can "relevance" solve the load vs success vs failure problem which has emerged from the findings of Streufert and associates?

A reinterpretation of the suggestions made by Streufert $(1970,1972)$ in terms of relevance research would suggest that failure information can produce increased relevance, i.e., a meaningful response to the information is possible not only once, but repeatedly to correct previous errors and to respond to current demands. In contrast, success information may be technically irrelevant; once a task has been successfully completed, additional task-oriented responses have no meaning. In the language of signal detection, failure information would provide more signals and less noise than success information.

While such a reinterpretation of research data adds clarity to the theoretical view, it also raises a more basic issue. If "relevance" can be separated from "load" (as experimental psychologists have done), then it is unreasonable to assume that the two affect decision making in the same way unless the similarity or identity of these variables has been demonstrated. Previous complexity based on research measuring the effects of information load on decision making has employed only relevant information, i.e., all information presented to the Ss at all load levels was relevant to their task. Consequently, previous results may have been due to either load or relevance, since load manipulations were perfectly confounded with relevance. The research reported in this paper represents the first attempt to disentangle the effects of the two variables on complex decision making.

One could argue that (1) previously obtained load effects on integrated decision making, respondent decision making, and information search are due to load effects and not to relevance effects, (2) the effects are due to information relevance and not to load, or (3) some of the effects are due to relevance and some are due to load. The latter prediction appears possible, since the measures of decision making employed by complexity theorists are orthogonal and substantially different from each other. While respondent decision making and information search are simple information-dependent (linear prediction) responses, integrated decision making is viewed as a more complex (curvilinear predictions) response which is dependent on the possibility to respond meaningfully to a series of information items.

The research reported in this paper was designed to test for the effects of information relevance on measures of complex decision making. Since relevance can only be varied as a proportion of load, and since the combined effects of load and relevance are known from past research, the best initial test of potential load-relevance differences would be a variation of relevance at a constant load level, moreover a load level which permits the dependent variables to vary. For that purpose, the load level which Streufert (1970) and Streufert and Schroder (1965) have shown to be "optimal" was selected (10 items of information per 30-min period) This load level has produced sufficiently high levels of respondent decision making to permit decreases and has produced intermediate levels of information search, permitting increases in that variable (as were found at lower levels of information load). In addition, this load level produced the highest output in integrated decision making. Since both higher or lower levels of load have in past research resulted in relatively low amounts of integrated decision making, a fair test of changes in that measure as a function of variation in relevance may not be possible at such super- or suboptimal load levels.

The following alternate predictions can be made: (1) If previously observed effects of information on complex decision making are due to variations in load alone, then no changes in any of the variables should be observed with increasing information relevance as a function of constant (optimal) load. (2) If previously observed effects are due to relevance alone, then an increasing proportion of information relevance within constant (optimal) load should (a) produce increasing integrative decision making, (b) produce increasing respondent decision making, and (c) produce decreasing information search (as obtained for load variation which was confounded with relevance in previous research). (3) If "simple" decision measures vary as a function of load and complex measures vary as a function of relevance, then increasing relevance as a proportion of 
constant (optimal) load should result in (a) increasing integrated decision making, (b) constant information search, and (c) constant respondent decision making.

\section{METHOD}

\section{Subjects}

Twenty-four male undergraduate students at a midwestern university, randomly selected from a course in psychology, participated in the tactical and negotiations game, an experimental simulation. The task was the same as that employed for previous research on effects of information load. Ss were paid $\$ 1 / \mathrm{h}$ of participation.

The Ss were assigned randomly to 12 dyad teams. Team members were instructed to act as national decision makers with responsibility for the military, economic, intelligence, and negotiation functions of a nation engaged in a limited war. Teams were told that they would be playing this internation game against a team representing an opposing nation. In reality, both teams were exposed to the same fixed input program. All teams were given equivalent funds and military facilities, although neither was informed of the resources of their "opponent" team.

\section{The Simulation}

The tactical and negotiations game (TNG) is an experimental internation simulation, permitting continuous $\mathrm{E}$ control of independent variables (cf. Fromkin \& Streufert, in press; Streufert, Kliger, Castore, \& Driver, 1967; Streufert, Castore, \& Kliger, 1967). This research setting tends to produce participant perceptions that are equivalent to experimentally induced conditions (Castore \& Streufert, 1966; Higbee \& Streufert, 1968). The experimental simulation has face validity (Streufert \& Streufert, 1969) and produces results that vary (where intended) with the experimental treatments (e.g., Higbee \& Streufert, 1968; Stager, 1967; Streufert \& Streufert, 1970; Streufert \& Castore, 1968).

Before beginning the experiment, each dyad team was placed in a room with a relief map of Shamba (a fictitious country on an unidentified peninsula). The room contained flags, progress charts, various national symbols and props, as well as the necessary game materials. The Ss were instructed to spend the first $2 \mathrm{~h}$ reading the players' manual, containing information about the history of Shamba, about current political, military, and economic conditions, and about other nations who might be "interested" in the Shamba conflict. ${ }^{2}$ Any assistance needed to understand the manual or game operations was given. Requests for assistance with initial decisions or strategy were not honored.

After the 2-h reading period, the TNG experimental simulation was begun. Teams were permitted to make any number of decisions (written on prepared forms), but were given a fixed number of (programmed) "reports on the outcome of their decisions" and reports about interactions with the "opposing team." The teams participated in four consecutive $1 / 2-h$ periods of play (each $1 / 2 h$ of real time represented $1 / 2$ year of game time). The Ss were not informed which playing period would be their last so that an end effect could be avoided. During each $1 / 2-\mathrm{h}$ playing period, they received 10 preprogrammed informative statements (messages) which were varied in relevance and content (see below). Ss were not aware, and did not suspect, that the information they received had been preprogrammed. As in previous research in this setting (Streufert \& Streufert, 1969), Ss attributed more than $80 \%$ of the conditions under which they were operating to combined effects of decisions of their own and decisions of the opposing team. Summed attributions of causality to "arbitrary decisions of the Es," "random factors," and "characteristics of the environment" remained below $20 \%$.

\section{Induction of Information Relevance}

Forty informative messages were preprogrammed for use in the simulation. All teams received the same messages. Twenty of these messages were relevant to the Shamba conflict (permitted the $\mathrm{Ss}$ to make decisions based on the information contained in such a message). For instance, a relevant message was. "Enemy troops are massing in the southeastern plains of Shamba." Twenty messages were not relevant to the Shamba conflict. For instance, an irrelevant message was, "The World Bank has announced an increase of funding of $3.4 \%$ over the last fiscal year."

Relevant and irrelevant informative messages were independently randomized for each team. They were then sorted so that each period of play would contain three messages of military, three of economic, three of diplomatic, and one of intelligence information, adding to 10 messages per period. Relevant informative messages were sorted into the four playing periods so that one of the periods contained two $(20 \%)$, another four $(40 \%)$. another six $(60 \%)$, and another eight $(80 \%)$ items of relevant information. The order of the four relevance periods was randomized for each team. Checks on the manipulation indicated that $S_{s}$ made more decisions based on relevant than on irrelevant information $(\mathrm{p}<.001)$ and that subjective perceptions of relevance increased in linear fashion with increases in experimentally induced relevance (Streufert \& Streufert, 1970).

\section{Measurement of Decision Making}

Three measures of decision making were employed in this research. All of these measures have been utilized in previous research on information load. The measures were chosen since (1) their orthogonality has been demonstrated in past research (Castore \& Streufert, 1968) and (2) they represent measures of "simple" and "complex" decision making.

The measures used were: (1) number of respondent (retaliatory) decisions, (2) number of integrations, and (3) number of decisions related to information search. Measure (2) reflects integrative quality of decision making, a complex form of decision making. Measures (1) and (3) reflect two different, simple forms of decision making. The method for obtaining the values of these measures for a team of $S s$ in any given TNG playing period has been described in detail by Castore and Streufert $(1967,1968)$ and others.

\section{RESULTS AND DISCUSSION}

Since the response frequencies for the three dependent measures of decision making are not meaningfully comparable with each other, the data obtained from each decision measure were analyzed separately with ANOVA procedures. No significance was obtained for relevance effects on respondent decision making $(F=2.03$, n.s., $\mathrm{df}=3 / 33)$ and information search decisions $(F=1.0, n . s ., \mathrm{df}=3 / 33)$. The analysis for number of integrated decisions resulted in a significant $F$ ratio $(F=5.76$, df $=3 / 33, p<.05)$. Post hoc Newman-Keuls analysis revealed significant differences between the 20\% relevance level [standard error of mean $\left.\left(s_{\bar{x}}\right)=.68\right]$ compared to the $60 \%\left(s_{\bar{x}}=\right.$ 1.07) amd $80 \%\left(s_{\bar{x}}=.85\right)$ levels. Results are shown graphically in Fig. 1 .

The results suggest that the previously obtained load effects on integrated decision making are likely due to information relevance. A relevance level of $80 \%$ within a 

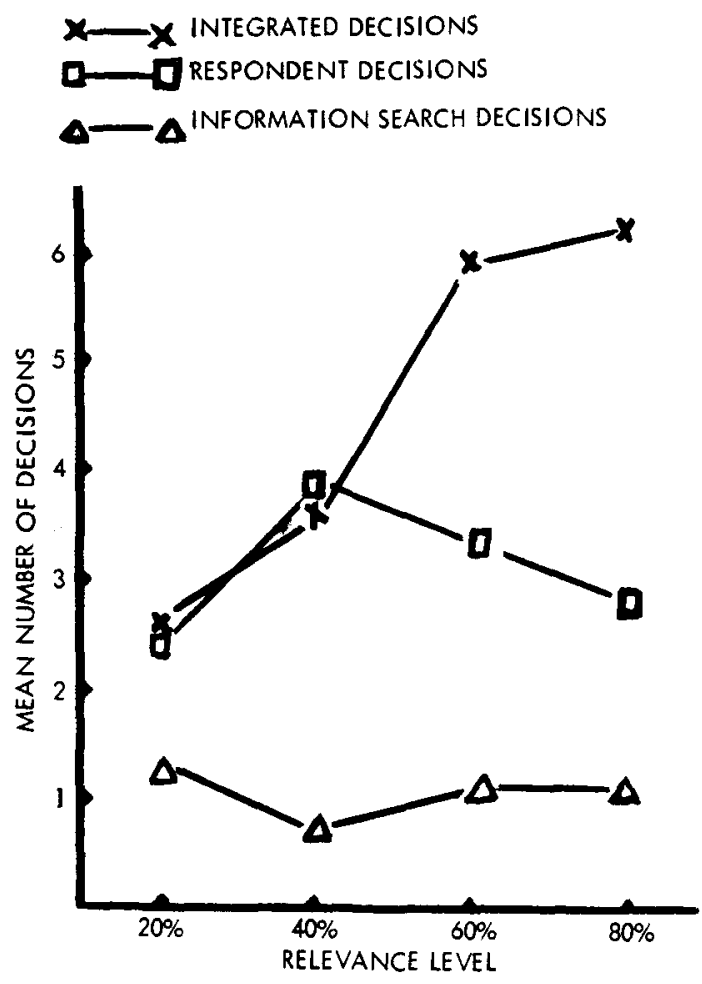

Fig. 1. Effects of information relevance on decision frequency.

load level of 10 items of information per 30-min period closely approximates the load level of 8 items of information, and the $20 \%$ level closely approximates the load level of 2 items of information per 30-min period which has been reported in past research (Streufert, 1970; Streufert \& Schroder, 1965). The finding that relevance had no effects on respondent decision making and information search decisions, combined with the absence of any consistent trends in the curves (see Fig. 1), suggests that relevance effects do not extend to the simpler decision measures. In other words, one might tentatively conclude that relevance levels and load levels affect decision making differentially: while information relevance variation modifies decision making characteristics which represent meaningful responses to the overall task (here integrated strategic responses), information load variation affects the simpler responses which tend to be made to the presence or absence of information proper.

The word "tentatively" is used with intent. If one wishes to test the effects of load and relevance in comparison to each other, one should ideally vary both through their entire range. Unfortunately, that is not possible. Information relevance is by necessity a function of the size of information load. Moreover, the curvilinear effect of information load on the integrative decision making measure prohibits testing for relevance effects at superoptimal and particularly at suboptimal levels. However, future research could probably test the linear effects (based on past load research) of load and effects of the relevance proportion of load on respondent decision making and information search at superoptimal information load levels.

In summary, it appears that the relevance concept might well be a useful addition to complexity theory. This seems particularly true since the theoretical difficulties encountered as a result of success and failure manipulations were produced by measures of integrative decision making. Translating success and failure into relevance would eliminate the theoretical shortcoming, leaving the "load" concept intact to account for variations in simpler forms of decision making.

\section{REFERENCES}

Burron, B. F., Carlson, K. A., Getty, G. R., \& Jackson, D. N. The effects of informational characteristics on the perception of real and hypothetical target persons. Psychonomic Science, $1971,23,145-147$.

Campbell, A. C. On introducing supraminimal data to items whose solution demands the use of indirect procedures. British Journal of Psychology, 1968, 59, 211-217.

Castore, C. H., \& Streufert, S. The perception of experimentally induced failure. Psychonomic Science, 1966, 4, 137-138.

Castore, C. H., \& Streufert, S. Components of decisions in a simulated environment. ONR Technical Report No. 2, 1967, Rutgers University.

Castore, C. H., \& Streufert, S. Decision making in an experimental internation simulation. ONR Technical Report No. 11, 1968, Purdue University.

Driver, M. J., \& Streufert, S. Group composition, input load and group information processing. Institute Paper No. 142, 1966 , Purdue University, Institute for Research in the Behavioral, Economic and Management Sciences.

Driver, M. J., \& Streufert, S. Integrative complexity: An approach to individuals and groups as information processing systems. Administrative Science Quarterly, 1969, 14 $272-285$

Edmonds, E. M., \& Mueller, M. R. Concept formation and utilization in the presence of irrelevant visual stimulation. Psychonomic Science, 1970, 18, 109-110.

Erlick, S. E. The ability to filter noise from a visual task when the noise and signal are presented sequentially. Journal of Experimental Psychology, 1962, 63, 111-114.

Fromkin, H. L., \& Streufert, S. Laboratory experimentation. In M. Dunnette (Ed.), Handbook of organizational and industrial psychology. Chicago: Rand McNally, in press.

Giambra, L. M. Effect of number of irrelevant dimensions with ten. concept types on the attribute identification task in the selection mode with exemplar and non-exemplar start cards. Psychonomic Science, 1969, 14, 75-76.

Goldstein, I. L., \& Allen, J. C. Effects of irrelevant stimuli on the processing of information in complex displays. Journal of Applied Psychology, 1971, 55, 110-113.

Higbee, K. L., \& Streufert, S. The perception of experimentallyinduced success. Psychonomic Science, 1968, 12, 361-362.

Hodge, M. H., \& Reid, L. S. The influence of similarity between relevant and irrelevant information upon a complex identification task. Perception \& Psychophysics, 1971, 10, 193-196.

Hyman, L. M. The effects of irrelevant dimensions and stimuli on two-choice discrimination learning by children. Psychonomic Science, 1971, 22, 249-250.

Kepros, P. G., \& Bourne, L. E., Jr. Identification of biconditional concepts: Effects of number of relevant and irrelevant dimensions. Canadian Journal of Psychology, 1966, 20, 198-207. 
Landis, D.. Slivka. R. M.. \& Silver. C. A. The effect of three types of visual irrelevancy on complex decision making. Journal of Psychology, 1970. 74. 29-42.

Morgan, B. B., \& Alluisi, E. A. Effects of discriminability and irrelevant information on absolute judgments. Perception \& Psychophysics, 1967, 2, 54-58.

Scandura. J. M. \& Voorhies. D. J. Effect of irrelevant attributes and irrelevant operations on rule learning. Journal of Educational Psychology, 1971, 62, 352-356.

Schroder. H. M.. Driver, M. J., \& Streufert. S. Human information processing. New York: Holt. Rinehart \& Winston. 1967.

Stager, P. Conceptual level as a composition variable in small group decision making. Journal of Personality \& Social Psychology, 1967, 5, 152-161.

Streufert, S. Increasing failure and response rate in complex decision making. Journal of Experimental Social Psychology, $1969,5,310-323$.

Streufert, S. Complexity and complex decision making. Journal of Experimental Social Psychology, 1970, 6, 494-509.

Streufert. S. Success and response rate in complex decision making. Journal of Experimental Social Psychology, 1972, 8, $389-403$.

Streufert. S.. \& Castore, C. H. Effects of increasing success and failure on perceived information quality. Psychonomic Science. 1968, 11, 63-64.

Streufert, S., \& Castore, C. H. Information search and the effects of failure: A test of complexity theory. Journal of Experimental Social Psychology, 1971, 7. 125-143.

Streufert. S., Castore, C. H.. \& Kliger, S. C. A tactical and negotiations game: Rationale, method and analysis. ONR Technical Report No. 1, 1967. Rutgers University.

Streufert, S., \& Driver, M. J. Conceptual structure, information load and perceptual complexity. Psy chonomic Science, 1965, 3, 249-250.

Streufert, S., \& Driver, M. J. Impression formation as a measure of the complexity of conceptual structure. Educational \& Psychological Measurement. 1967, 27. 1025-1029.

Streufert, S., Driver, M. J., \& Haun, K. W. Components of response rate in complex decision making. Journal of Experimental Social Psychology, 1967, 3, 286-295.

Streufert, S., Kliger, S. C., Castore, C. H., \& Driver, M. J. A tactical and negotiations game for the analysis of decision integration across decision areas. Psychological Reports. 1967, $20,155-157$

Streufert, S., \& Schroder, H. M. Conceptual structure. environmental complexity and task performance. Journal of Experimental Research in Personality. 1965. 1. 132-137.

Streufert. S.. \& Streufert. S. C. The effect of conceptual structure, failure and success on attribution of causility and interpersonal attitudes. Journal of Personality \& Social Psychology, 1969, 11, 138-147.

Streufert, S., \& Streufert, S. C. The perception of information relevance. Psychonomic Science, 1970, 18, 199-200.

Streufert. S., Suedfeld, P., \& Driver, M. J. Conceptual structure. information search and information utilization. Journal of Personality \& Social Psychology, 1965, 2. 736-740.

Tresselt, M. E. The effect of partially irrelevant anchors on verbal conceptual thinking. Psychonomic Science, 1969, 16, 312-313.

Well, A. D. The influence of irrelevant information on speeded classification tasks. Perception \& Psychophysics, 1971, 10 , 79-84.

Williges, R. C. The role of payoffs and signal ratios in criterion changes during a monitoring task. Human Factors, 1971, 13. 261-267.

\section{NOTES}

1. It might be useful to distinguish between research on information relevance and research concerned with concepts based on information theory. "Relevant" information is information that permits meaningful responding on the part of the receiver. This response may occur as a result of either increases or decreases in uncertainty. Although much research on information relevance has indeed utilized information that did reduce uncertainty, not all theorists or researchers concerned with relevance have used or approximated information theory paradigms. The approach to information relevance used in this paper will not employ the $\mathrm{H}$ statistic. in part because uncertainty reduction in multidimensional interactive environments is not easily subjected to such an approach. Reducing uncertainty on one perceptual (or behavioral) dimension might well increase uncertainty on another.

2. Having $\mathrm{S} s$ spend $2 \mathrm{~h}$ reading the manuals had two primary purposes: (1) to familiarize the teams with the Shamba conflict and the supplies and facilities available to them, and (2) to help equalize immediate preexperimental experiences of the Ss.

(Received for publication December 2, 1972; revision received January $19,1973$. ) 